\title{
The role of informational, normative, and avoidance identity styles in prediction of social anxiety in medical science students
}

Farideh Daneshniya ${ }^{1}$, Sharareh Zarabi ${ }^{2}$, Zahra Karimiyan ${ }^{3}$

\author{
Journal of Research \& Health \\ Social Development \& Health Promotion \\ Research Center \\ Vol. 8, No. 1, Jan \& Feb 2018 \\ Pages: $32-37$ \\ DOI: 10.29252/acadpub.jrh.8.1.32 \\ Original Article
}

1. Correspondence to: Department of Psychology, School of Psychology, Islamic Azad University of Khorasegan, Isfehan, Iran Email: Daneshniafarideh@gmail.com

2. Department of Psychology, School of Psychology, Islamic Azad University of Naein, Isfehan, Iran

3. Department of Psychology, School of Psychology, Islamic Azad University of Najafabad, Isfehan, Iran

Received: 26 Jun 2016

Accepted: 6 Nov 2016

How to cite this article: Daneshniya F, Zarabi Sh, Karimiyan Z. The role of informational, normative, and avoidance identity styles in prediction of social anxiety in medical science students of Isfehan University (Iran). $J$ Research \& Health2018; 8(1): 32- 37.

\begin{abstract}
Social anxiety is a psychological disorder affected by cognitive aspects of person. The aim of study was to investigate the role of informational, normative, and avoidance identity styles in predicting the variance of social anxiety amongst Iranian medical science students. Using stratified sampling method, one hundred and twenty students were selected from each of the colleges of medicine, pharmacy, nursing, and public health. Berzonsky identity style questionnaire, and Liebowitz et al social anxiety test were used for data collection. According to obtained results informational, normative, and avoidance identity styles can predict the variance of social anxiety. Moreover, there was a significant and negative correlation between social anxiety and informational style and normative identity style; Meanwhile, there was a positive significant correlation between social anxiety and avoidant identity style. With respect to findings of current study, providing more opportunities in the colleges and faculty is recommended in order to improve informational and normative identity styles among students, and reduce social anxiety consequences.
\end{abstract}

Keywords: Identity, Social Anxiety, Student

\section{Introduction}

Anxiety disorders are the most common psychiatric disorders both in primary care and in clinical medicine. Studies constantly have shown that anxiety disorders cause many complications and problems such as disruption in educational attainment at school or university and disrupt in job performance and social development. Spending high levels of health care on their own dramatically can reduce the quality of life and function in a person [1].

Social anxiety is recognized by a continuous panic of one or several social; situations in which people think their performances and behaviors are monitoring by other people, thus, they refrain from social situations. Social anxiety is recognized by some physiological traits (red cheeks, perspiration dried mouth and trembling bodies when attending in a stressful social situation) psychological traits (sham, embarrassment, panic of possible mistake sand negative judgment and criticism by other people), and behavioral traits (aloofness, 
refraining from visual contacts, panic of selfexpression and talking in a social situation or being addressed by other people) [2].

Social Anxiety Disorder (SAD) is the third psychiatric disorder with a prevalence of $2.4 \%$ up to $16 \%$ [3]. It is obvious that without treatment, social anxiety can significantly disturb occupational, educational, and social abilities of people [4].

This disorder is linked with disruption in emotion, professional and interpersonal relations [5,6], quality of life [7], friendships and romantic relationships $[8,9]$, and it start before other anxiety disorders, mood disorders and disorders caused by drug abuse [10].

Therefore, it is essential that before disorder becomes chronic, reasons of it should be identified. One of the psychological factors associated with social anxiety, is identity styles. Lack of confidences to create identity and doubt could be cause of anxiety disorder, Because of social anxiety disorder, patients spot fear of negative evaluation as a threat to their personal capacity and thus experience stress and anxiety. However, someone with established identity, these evaluations don't endanger their personalities; consequently, they don't afflict to consternation and phobic [11]. Erikson defines the identity as a relative stable feeling of isolation, thus, in spite of behaviors, thoughts and feelings; personal perception is always same [12].

Berzonsky [13] said that identity is personal frame for explanation experiences. He believed that identity style is differences between persons in making decisions, solving problem and discover information. Therefore, he presents informational styles, normative styles and avoidant styles. Informational styles is related to self reflection, focus on the issues, epistemology, need to cognition, make decision, caution and openness to experiences [14]. People have normative styles conform to value and exceptions of important persons [15]. People have avoidant styles react to demands of position continually. There is hypothesis about self that said they will have to neglect and avoid from conflicts and personal decisions [16].
Similar investigations and studies about the matter are considered;

Study of Stein et al showed that people with social anxiety in compared to people non-anxious suffering from disruptions in academic and professional performance [17]. Results of study of Rahiminejad et al showed that informational style and normative style have negative effect on anxiety through identity, and avoidant style has positive effect on social anxiety through identity [18]. Results of research of Vaziri \& Lotfi Kashani showed that psychosis have negative relation with informational style and normative style and positive relation with avoidant style [19]. Results of study's Aghamohammadian \& Sheikh Roohani showed that people haven't commitment in ideological and interpersonal aspects suffering from higher levels of anxiety [11]. Research of Sterling \& Vanhom showed that anxiety has positive correlation with identity confusion [20]. There are many challenging during studying in university for students, that for faced to stressful situations and proper adjustment to achieve academic and professional prosperity, it is essential to make high level of mental health in social group [21].

Because of importance of identity formation in people's lives and its role in the mental health, it is essential to survey the role of formation of identity and lack formation identity with related disorders in period of life. Although there are quantitative research in this field but, students of medical science have important role in mental health of society, therefore, it is necessary to review the level of disorder and style of identity among them. Thus, investigation on social anxiety which is an effective factor to mental health and related factors can improve significantly mental health amongst the students. One the other hand, because of more exposure with patients and clinical cases, students of medical science encounter with a variety of social anxiety. Therefore, by considering the importance of the topic, we conducted an investigation to detect the correlation identity styles together 
with social anxiety amongst the medical science students of Isfehan University (Iran). Thus, this research yields an investigation to the assumption below:

Informational, normative, and avoidant identity styles can predict the variance of social anxiety.

\section{Method}

The method of this study was descriptive -correlation type. The populations of this research were all medical science students of Isfehan University during 2015 \& 2016. For select students who have social anxiety, we used questionnaire of Liebowitz et al. Thus students, who achieve two standard deviation higher of the mean in this scale, have chosen for this study. Then, they filled out identity styles questionnaire. The samples are 120 students selected by stratified random sampling. From each of the faculty Medicine, Pharmacy, Nursing \& Public Health, thirty students were selected.

The inclusion criteria included:

The participants had discretion to cooperate and their consent was obtained orally. The social anxiety scale score of two standard higher of the mean. And using no from any psychiatric drug. Age ranges of 20_40 years.

The exclusion criteria included:

Unwillingness to cooperate in research. Physical illnesses

The following instruments were used to gather information:

Social anxiety questionnaire: This questionnaire was designed by Liebowitz et al [22], and including 24 items to investigate anxiety in social counter actions (11 items) and social situations (13 items). In section evaluating panic, score (0) was assigned for never (lack of panic) and score (3) was assigned for intense (intense panic). In section that evaluating refrainment, score (0) means never (no refraining) and score (3) means normally (intense refraining). This questionnaire reports the social anxiety at four levels, middle (55 to 65 ), considerable (65 to 80 ), intense ( 80 to 95 ), and very intense (over 95). To evaluate the scientific validity of the tool, casual validation and content method were used and was verified by specialists and Chronbach Alpha coefficient was 0.97 [23]. In this study, the reliability was calculated using Cronbach's Alpha 0.70

Berzonsky identity styles questionnaire in 1992: This questionnaire includes 40 questions and evaluates the level of obligation and identity styles. 11 out of 40 items relate to the informational identity, 9 items to the normative identity style, 10 items to the diffuse avoidant style, and 10 items evaluate the level of personal obligation used for secondary analysis which is not an identity style; therefore, it was not used in this research. The answers include Five-Degree Lickret spectrum including completely, completely agree, no idea, disagree \& completely disagree. Items of $9,11,14 \& 20$ were scored inverse other items in this scale. White et al checked the validity of this questionnaire and the findings were as follow: informational identity style correlation was $81 \%$, normative identity style was $85 \%$, perplexed identity style was $85 \%$, and obligation was $86 \%$ [24] .Vaziri \& Lotfi Kashani reported the general stability of scores in informational identity style; 0.84 , normative identity style; 0.69 , and avoidant style; 0.53 [19]. The reliability was calculated using Cronbach's Alpha ( $\mathrm{r}=0.81)$.

To analyze data, SPSS (V-19) were used and Pearson correlation coefficient test and simultaneously multiple regressions were run to determine the correlation between variables.

\section{Results}

According to the study, $60 \%$ of students were single and $40 \%$ were married. Average age of students was $25.5 \pm 3$.

Mean and standard deviation of social anxiety $41.51 \pm 28.8$, informational style $32.52 \pm 5.22$, normative style $26.64 \pm 3.99$ and avoidance style $30.35 \pm 4.5$.

Results showed that $30 \%$ of students had anxiety minor, $60 \%$ had considerable anxiety, $9 \%$ had middle anxiety, and $1 \%$ had severe anxiety.

There was a negative and significant 
correlation between social anxiety and styles of informational identity $(\mathrm{r}=0.789)$, and normative identity $(\mathrm{r}=0.824)$. There was a positive and significant correlation between social anxiety and avoidant identity style $(\mathrm{r}=0.838),(\mathrm{p}<0.001),($ Table 1$)$.

Table 1 The correlation of social anxiety and identity styles

\begin{tabular}{lcc}
\hline \multirow{2}{*}{ Variables } & \multicolumn{2}{c}{ Social anxiety } \\
\cline { 2 - 3 } & Coefficient correlation & Sig \\
\hline Informational Style & -0.789 & 0.001 \\
Normative Style & -0.824 & 0.001 \\
Avoidance Style & 0.838 & 0.001 \\
\hline
\end{tabular}

As it is clear form Table 2, observed $\mathrm{F}(\mathrm{F}=222.109$, $\mathrm{p}<0.001$ ) was significant and $85.2 \%$ of variance

of the social anxiety was predictable by various identity styles $\left(R^{2}=0.852\right)$.

Table2 Summary of regression model and results of analysis of variance

\begin{tabular}{|c|c|c|c|c|c|c|c|c|}
\hline Model & $\mathrm{R}$ & $\mathrm{R}^{2}$ & $\begin{array}{c}\text { Source } \\
\text { Variance }\end{array}$ & $\begin{array}{l}\text { Sum of } \\
\text { Squares }\end{array}$ & df & $\begin{array}{l}\text { Mean } \\
\text { Square }\end{array}$ & $\mathrm{F}$ & Sig \\
\hline Informational style & & & Regression & 43625.88 & 3 & 14541.96 & & \\
\hline Normative style & 0.923 & 0.852 & Residual & 7594.78 & 116 & 65.47 & 222.109 & 0.001 \\
\hline Avoidance style & & & Total & 51220.66 & 119 & & & \\
\hline
\end{tabular}

Informational and normative styles could predict variance of social anxiety negatively in level of $\mathrm{p}<0.001$, but, avoidant style could predict variance of social anxiety positively in level $p<0.001$ :

Table 3 Identifying the role of each style in prediction of social anxiety

\begin{tabular}{lcccc}
\hline Model & $\mathrm{B}$ & Beta & $\mathrm{T}$ & Sig \\
\hline Constant & 168.77 & - & 30.58 & 0.001 \\
Informational style & -1.237 & -0.312 & 6.137 & 0.001 \\
Normative style & -1.675 & -0.323 & 5.75 & 0.001 \\
Avoidance style & 1.852 & 0.406 & 7.50 & 0.001 \\
\hline
\end{tabular}

\section{Discussion}

This study showed that informational, normative, and avoidance identity styles can predict the social anxiety.

The results of this research are consistent with studies conducted by Rahiminejad et al [18], and Aghamohammadian \& Sheikh Roohani [11]. Using normative and informational styles lead to receiving unification and distinction from information sources and subsequently suffering from lower level of social anxiety, In avoidant identity styles, because of refraining from social situations, and no social anxiety was experienced.

Results revealed a negative and significant correlation between informational style and social anxiety, which was consistent with the results of Rahiminejad et al [18], Vaziri \& Lotfi Kashani [19], and Aghamohammadian \& Sheikh Roohani [11]. Existence informational identity style made persons to focus on topic and problem directly. On the other hand, using rational style brought about decision making based on the wisdom, and innovative ideas in dealing with anxiety. These participants could reduce anxiety in social situations, because they had appropriate relationships with others. Participants with informative identity style were thoughtful and introspective and cognitively functioned very well in stressful situations. They judged according to their criteria, and were less dependent to opinions of others for their decisions which led to experiencing less anxiety in social situations.

There was a significant and negative correlation between normative identity style and social anxiety is consistent with the results of Rahiminejad et al [18], and Vaziri \& Lotfi Kashani [19], and Aghamohammadian \& Sheikh Roohani [11]. Participants used 
their normative identity style, in dealing with anxiety, tended to consult with powerful people in solving problem and choosing the solutions, therefore, they encountered with anxiety by eluding the events or situations that did not endorse their view or support their views, in order to reduce their anxiety in social situations. They were conscientious and purposeful, but they were highly structured, that, this help them for protect against anxiety.

Furthermore, a positive and significant correlation was observed between avoidant and social anxiety. This finding was consistent with results held by Rahiminejad et al [18], Vaziri \& Lotfi Kashani [19], Aghamohammadian \& Sheikh Roohani [11], and Sterling \& Vanhorn [20]. Participants with avoidant identity style tried to delay conflict situations requiring decisions, Sometimes they resorted to decisions considering environmental implications, had sense of fear and anxiety in determinant important decision, and used maladaptive strategies such as avoidance, excuse, and rationalization, depended on the position, and didn't have antiseptic pattern. This identity style correlated with emotion-oriented style, poor decisionmaking strategies, self-limited, and usage of inefficient cognitive strategies; therefore, level of anxiety in these subjects was high.

When they were forced to make decisions, they acted based on situation-emotional style, and were affected by its immediate consequences. Subsequently, social anxiety was very high among them.

\section{Conclusion}

Since student's identity is shaped during education, providing opportunities for growing informational and normative identity styles with less social anxiety consequence is recommended in the colleges and faculty. Further studies are suggested to examine identity styles accompanied with a variety of anxiety disorders.

Because this study was conducted on a limited number of students, the results can 'not bed generalized for all students. On the other hand, this study was a correlative study and the association between cause and effect cannot be extracted.

\section{Contribution}

Study design: FD

Data collection and analysis: SZ

Manuscript preparation: ZK

\section{Conflict of Interest}

"The authors declare that they have no competing interests."

\section{Acknowledgements}

The authors thanks to students who worked in this study.

\section{Funding}

The author (s) received no financial support for the research, authorship and/or publication of this article.

\section{References}

1- Sadock HS, Sadock BJ. Synopsis of psychiatry: behavioral Sciences/Clinical Psychiatry. Philadelphia: Lippincott Williams \& Wilkins; 2007.

2-Stravynski A, Bond S, Amado D. Cognitive causes of social phobia: A critical Appraisal. Clin Psychol Rev2004; 24(2), 421-40.

3- Acarturk C, Smit F, De Graaf R, Van Straten A, Ten Have M, Cuijpers P. Economic costs of social phobia: A population-based Study. J Affect Disord2009; 115(3): 421-9.

4- Davis TE, Munson MS, Tarcza EV. Anxiety disorders and phobias. In Maston JL, eds. Social behavior and skills in children. New York; Springer-Verlag; 2009. pp: 219-43.

5- Ledley DR, Heimberg RG. Social anxiety disorder. In: Antony MM, Ledley DR, Heimberg R, eds. Improving outcomes and preventing relapse in cognitive-behavioral therapy. New York: Guilford press; 2005. pp: 38-76.

6- Katzelnick DJ, Kobak KA, Deleir T, et al. Impact of generalized social anxiety disorder in managed care. Am J Psychiatry2001; 158(12): 1999-2007.

7- Lochner C, Mogotsi M, Du Toit PL, Kaminer D, Niehaus DJ, Stein DJ. Quality of life in the anxiety disorder a comparison of obsessive compulsive disorder, social anxiety disorder, and panic disorder. Psychopathology2003; 36(5): 255-62.

8- Antony MM, Roth D, Swinsom RP, Huta V, Devins GM. Illness intrusiveness in individuals with panic disorder, obsessive -compulsive disorder, or social 
phobia. J Nerv Ment Dis1998; 186(5): 311-5.

9- Whishman M, Sheldon C, Goering P. Psychiatric disorder and dissatisfaction with social relationships: does type of relationship matter? J Abnorm Psychol2000; 109(4): 803-8.

10- Lampe L, Slade T, Iissakidis C, Andrews G. Social phobia in the Australian National Survey of mental health and Well-Being (NSMHWB). Psychol Med2003; 33(4): 637-46.

11- Aghamohammadian SH, Sheikh Roohani S. Investigating the Relationship between Identity Status and Anxiety. Daneshvar Raftar2009; 16(37): 9-20.

12- Erikson E. Childhood and society. New York: Norton; 1963.

13- Berzonsky M. Identity processing style, selfconstruction and personal epistemic assumption: A socialcognitive perspective. Eur J Dev Psychol2004; 1(4): 303 15.

14- Ongen DE. The relationship among perfectionism, self criticism and identity style in Turkish University student. Procedia Soc Behav Sci2011; 30, 565-72.

15- Omidian M. Identity from the psychological perspective. Yazd: Yazd University press; 2009.

16- Hashemi S. A study of identity styles and commitment of students based on identity construction model of Berzonsky and their correlation with wisdom-related knowledge in the process of problem solving. Quarterly Journal of Psychological Studies2014; 10(1): 109-36. 17- Stein MB, Torgrud LJ, Walker JR. Social phobia symptoms, subtypes and severity findings from a community survey. Arch Gen Psychiatry2000; 57(11): 1046-52.

18- Rahiminejad A, Borjaliloo S, Yazdani Varzaneh MJ, Farahani H, Amani H. The effect of identity styles on undergraduates' depression, anxiety and stress in students: mediating role of identity commitment. Journal of Psychological Models and Methods2012; 2(9): 1-15.

19-Vazari Sh, Lotfi Kashani F. Identity Styles and Psychological Distress. Journal of Clinical Psychology Andishe va Raftar2013: 7(26): 77-86.

20- Sterling C, Vanhorn R. Identity and death anxiety. Adolescence 1989; 24: 321-6.

21- Zare N, Daneshpajooh F, Amini M, Razeghi M, Fallahzadeh MH. The relationship between self-esteem, General Health and Academic Achievement in students of Shiraz University of Medical Sciences. Iranian Journal of Medical Education2007; 7(1): 59-67.

22- Liebowitz MR, Quitkin FM, Stewart JW. Phenelzine $\mathrm{v}$ imipramine in atypical depression. A preliminary report. Arch Gen Psychiatry1984; 41(7): 669-77.

23- Ghezelbash S, Peyrovi H, Inanloo M, Haghani

H. Relationship between Social Anxiety and Some Demographic Characteristics among Nursing Students. Journal of Health and Care2015; 17(1): 19-29.

24- White JM, Wampler RS, Win KI. The identity style Inventory: A revision with a sixth grade reading level (ISI-6G). J Adolescent Res1998; 13(2): 223-42.

Copyright $(2016$ ASP Ins. This open-access article is published under the terms of the Creative Commons Attribution-NonCommercial 4.0 International License which permits Share (copy and redistribute the material in any medium or format) and Adapt (remix, transform, and build upon the material) under the Attribution-NonCommercial terms. 